\title{
DE LOS PARQUES NACIONALES A LA CONSERVACIÓN DE LA BIODIVERSIDAD
}

\author{
FERNANDO LÓPEZ RAMÓN \\ Catedrático de Derecho Administrativo \\ Universidad de Zaragoza
}

\begin{abstract}
RESUMEN
Valoración crítica de la evolución experimentada por el régimen de protección de la biodiversidad desde el ingreso de España en la CEE (1986). Se encontraba entonces vigente la LENP de 1975, que la Administración forestal defendía en su intento de monopolizar las funciones públicas relativas a la conservación de la naturaleza. No obstante, el compromiso constitucional en materia de medio ambiente, así como la variada actividad de las CC. AA. en defensa de los valores de sus respectivos territorios, terminarían fraguando en la legislación básica de 1989, que asumió ya planteamientos conservacionistas. Finalmente, las exigencias comunitarias establecidas en las directivas de Aves (1979) y Hábitats (1992) configuraron un verdadero sistema general de protección de la biodiversidad a través de la red Natura 2000. En el estudio se explica el significado de dicha red, prestando especial atención al alcance de las obligaciones estatales y a los problemas derivados de la tardía e incompleta incorporación de las Directivas citadas. Se mantiene la tesis de la necesidad de desarrollar plenamente la red Natura 2000 para hacer de la misma el eje de la política española de conservación de la biodiversidad.
\end{abstract}

Palabras clave: parques nacionales; espacios naturales protegidos; Red Natura 2000; directiva de aves; directiva de hábitats.

\begin{abstract}
Critical review of the evolution of the legal regime concerning the protection of biodiversity since the accession of Spain to the EEC (1986). The law in force at that moment, the LEPN of 1975, had the support of the Public Administration with competences in forestry, which regarded the LEPN as an instrument to maintain its monopoly in the policy of nature conservation. However, the constitutional commitment on environmental issues, together with the Autonomous Regions' actions in support of the environmental values in their respective territories, led to the nature conservation legislation of 1989, which had a conservationist approach. Finally, the Community requirements of the Birds Directive (1979) and the Habitats Directive (1992) configured a true general system of protection of biodiversity through the Natura 2000 network. The paper explains the meaning of this network, paying particular attention to the scope of the State obligations and to the problems derived from the late and incomplete transposition of the above mentioned Directives. The main conclusion is the need of a full development of the Natura 2000 network in
\end{abstract}


order to make it the axis around which the Spanish policy of protection of biodiversity should revolve.

Key words: National Parks; natural protected areas; Natura 2000 Network; birds directive; habitats directive.

\section{SUMARIO}

I. El lamentable panorama de la conservación al ingResar en la CEE.-II. La DESCOORDINADA REACCIÓN AUTONÓMICA.-III. LA TARDÍA LEGISLACIÓN BÁSICA CONSERVACIONISTA.- - IV. El SIGNIFICADO DE LA RED NATURA 2000.-V. La PROBLEMÁTICA INCORPORACIÓN AL ORDENAMIENTO ESPAÑOL.-VI. PERSPECTIVAS DE LA CONSERVACIÓN DE LA BIODIVERSIDAD.-VII. ORIENTACIÓN BIBLIOGRÁFICA.

\section{El LAMENTABLE PANORAMA DE LA CONSERVACIÓN AL INGRESAR EN LA CEE}

En 1986, al producirse el ingreso de España en la CEE, la conservación de la naturaleza era objeto de una tibia atención en la Ley de Espacios Naturales Protegidos de 1975. Dicha ley puede considerarse como la culminación de las aspiraciones de dominio corporativo de la Administración forestal, una vez alcanzada su autonomía organizativa a través del ICONA, que impuso su visión limitada de la conservación desde su creación en 1971 hasta su supresión en 1995.

El camino de la conservación se había iniciado con la Ley de Parques Nacionales de 1916, que perseguía proteger «sitios o parajes excepcionalmente pintorescos, forestales o agrestes». Criterios estéticos de limitado alcance que quizá hubieran podido evolucionar fácilmente hacia intervenciones más activas, en particular una vez que la «belleza natural» fue objeto de tutela en la Constitución republicana de 1931 (art. 45). Sin embargo, lo que se impuso en nuestra historia, decididamente tras la Guerra Civil, fue la "forestalización», pues las competencias sobre los parques nacionales y las demás figuras protectoras fueron engullidas por la poderosa Administración de montes como una de tantas funciones que tradicionalmente venía desempeñando. Las mismas personas y los mismos órganos que se encargaban de regir las intervenciones estatales en materia de aprovechamientos forestales, caza o pesca fluvial, actividades todas que pueden incidir negativamente sobre la naturaleza, asumieron la tarea de su defensa.

La maquinaria forestal llegó a imponer incluso la derogación formal de la vieja Ley de Parques Nacionales de 1916 por la Ley de Montes de 1957. Toda una filosofía acerca de lo que debía ser la protección de la 
naturaleza, traducida en la idea del bosque como objeto de explotación controlada, podía encontrarse expresada en el hecho de que la regulación de los parques nacionales se contuviera en el mismo título que la Ley de Montes dedicaba a las industrias forestales. Quizá no sea inútil recordar que la conservación de la naturaleza constituye una función pública difícilmente compatible con su ubicación exclusiva en el ámbito forestal, pues forman parte de ella no sólo los montes sino también los ríos, las costas, el mar, e incluso los terrenos agrícolas.

En el ámbito de las actuaciones propiamente conservacionistas, la declaración del Parque Nacional de Doñana en 1969 asumió un importante valor testimonial de las contradicciones que presentaba la actuación de la Administración de montes. Así, por una parte, ha de destacarse que se trataba del primer parque no propiamente forestal al ubicarse en una amplia marisma que, como casi todas las zonas húmedas, había venido siendo objeto de actividades de desecación. La declaración del Parque Nacional de Doñana, en consecuencia, era un acontecimiento en el devenir de la función pública de conservación: por primera vez en nuestra historia un ámbito marismeño dejaba de ser considerado como un foco infeccioso requerido de transformación para constituirse en objeto directo de la protección pública.

Sin embargo, la consideración tanto del proceso determinante de la declaración de Doñana como de la gestión posterior del espacio dan lugar a abundantes perplejidades. Desde el año 1957, al menos, después de que una expedición científica europea comprobara los extraordinarios valores naturalistas del antiguo cazadero, la necesidad de proteger Doñana se convirtió en un objetivo primordial para la comunidad internacional. Ante la incomprensión de la Administración forestal, en 1964 el $W W F$ hubo de prestar ayuda económica al CSIC para adquirir el terreno con el que se formó la Estación Biológica de Doñana. En adelante, la actuación decididamente conservacionista de los sucesivos directores de la estación, que contrastaba con las posturas burocráticas de la Administración forestal, derivó en su abierta oposición a los diversos proyectos de desecación, de construcción de carreteras y de urbanización que, entre otros, han caracterizado los problemas del Parque Nacional de Doñana.

Mientras tanto, impulsos proteccionistas procedentes del exterior del país incidían en todas estas cuestiones, destacadamente a partir de la Conferencia de las Naciones Unidas sobre el Medio Humano (Estocolmo, 1972). De una intervención limitada a la conservación de algunos espacios selectos se estaba pasando a la formación de una función pública general de protección del medio ambiente, cuyas aspiraciones 
conservacionistas no se ceñían ya a los lugares excepcionalmente bellos o pintorescos, sino que pretendían abarcar toda la gestión de los recursos y espacios naturales. En ese importante contexto mundial de cambio, las tradicionales Administraciones forestales de diversos países, a las que se había vinculado la gestión de los escasos terrenos protegidos como parques nacionales o figuras afines, experimentaron una auténtica conmoción al vislumbrar el peligro, para los respectivos intereses corporativos, de una pérdida progresiva de funciones.

En la experiencia española el fenómeno puede observarse en la creación del Instituto Nacional para la Conservación de la Naturaleza (ICONA) por Decreto Ley en 1971. Con esa fórmula organizativa revestida del ropaje supuestamente renovador de una denominación atractiva, la Administración de montes culminó sus aspiraciones corporativistas. La vieja Dirección General de Montes, Caza y Pesca Fluvial y sus organismos autónomos (el Patrimonio Forestal del Estado y el Servicio Nacional de Pesca Continental, Caza y Parques Nacionales) dieron paso a un organismo autónomo dotado de vastas competencias sobre los recursos naturales renovables en general, y específicamente sobre los montes, los incendios forestales, el suelo, las vías pecuarias, los parques y sitios nacionales, la caza y la pesca continental.

Las amplias posibilidades que las anteriores competencias brindaban para el desarrollo de una política activa de protección de la naturaleza resultaron, sin embargo, escasamente utilizadas. El ICONA se iba a constituir, conforme a las tradiciones burocráticas que asimilaba y potenciaba, en una rémora para la conservación. Habría sido preciso establecer unas estructuras administrativas verdaderamente renovadas, no controladas exclusivamente por los técnicos forestales. La conservación de la naturaleza no podía seguir ya configurándose como un mero apéndice de la intervención forestal, tanto por la indudable presencia de otros ámbitos precisados de una adecuada tutela (las aguas, las costas, las marismas) como por el mismo lastre que suponía mezclar la gestión económica de los recursos naturales con las tareas de su protección.

La regulación completa de la materia que cabe vincular a los planteamientos del ICONA fue la ya citada LENP de 1975, norma de muy pocos vuelos, de tono burocrático, escasamente innovadora, demasiado prudente ante los derechos de propiedad, poco rigurosa en el manejo de los conceptos jurídicos y claramente centralista en sus previsiones organizativas. La esclerosis del sistema de intervención sobre la naturaleza vinculado a la Administración de montes propició el uso de otros instrumentos, desde los ámbitos de la protección del patrimonio cultural y el urbanismo, para proteger los espacios naturales. 
Tal era el panorama legislativo y administrativo todavía vigente en 1986. No obstante, ya entonces se advertían síntomas de renovación, primero entre las comunidades autónomas y luego, bajo el directo influjo de las exigencias comunitarias, por parte del Estado.

\section{LA DESCOORDINADA REACCIÓN AUTONÓMICA}

Los planteamientos centralizadores, ampliamente arraigados en las estructuras estatales y aun en una parte del movimiento ecologista, sorprenden por su contraste con la débil actuación proteccionista del Estado. En efecto, el conjunto de las intervenciones estatales a lo largo de nuestra historia en materia de conservación de la naturaleza, en modo alguno permite a los órganos estatales competentes presentar una brillante o, al menos, meritoria hoja de servicios que les haga acreedores ni de las pretensiones corporativas ni de la confianza ecologista: 15 parques nacionales y 19 espacios naturales de otras categorías constituyen su legado conservacionista a las comunidades autónomas. ¿De dónde, pues, surge la prepotencia centralista?

Frente al decepcionante panorama deparado por la intervención histórica del Estado, la opción descentralizadora confirma desde sus inicios, si no una situación idílica, al menos, un mosaico de interesantes y significativos esfuerzos en materia de conservación de la naturaleza. Ha habido y hay de todo en la actuación de las comunidades autónomas, pero de manera generalizada cabe constatar el establecimiento de políticas de defensa del territorio. Con muchos desfallecimientos, es verdad, aunque, desde luego, no con mayores ni con más significativas inconsecuencias que las identificables en la gestión estatal. Así, ya en el año 2000 se calculaban en 650 los espacios protegidos por impulso autonómico y local.

Marginando ahora los abundantes problemas surgidos en relación con la distribución de competencias sobre los espacios naturales protegidos, hay que decir que, en la época de nuestro ingreso en la CEE, la actuación de la mayor parte de las comunidades autónomas en esta materia se caracterizaba por cierta atonía: algunas asumieron la gestión de los escasos parques naturales existentes tras los correspondientes traspasos por el Estado, y otras procedieron a declarar (por ley o por decreto) algún nuevo espacio natural protegido (en varios casos sobre el territorio de antiguas reservas nacionales de caza) conforme a lo previsto en la Ley de Espacios Naturales Protegidos de 1975.

Pero también hubo comunidades autónomas más dinámicas, que llegaron a aprobar leyes generales mediante las que impulsaban la con- 
servación de la naturaleza en sus territorios. Se trata de las Leyes de Baleares de 1984, de Cataluña de 1985, de Navarra de 1987, de Canarias de 1987 y de la Comunidad Valenciana de 1988.

La idea de red natural, entendida como un conjunto de espacios naturales cuya selección obedece a criterios científicos sobre los grandes ecosistemas y en cuya gestión prima la coherencia del propio conjunto, todavía no estaba completamente asumida. Sin embargo, las técnicas urbanísticas proporcionaban elementos que fomentaban el acercamiento a esos planteamientos. Al mismo tiempo encontramos ya en algunas de estas primeras leyes autonómicas (Cataluña, Navarra) intentos de conformar sistemas generales de conservación de la naturaleza, con el foco de atención en las necesidades de todo el territorio de la respectiva comunidad autónoma y no solamente en las de algunos territorios especialmente protegidos. Pero, incluso cuando las regulaciones se decantaron exclusivamente por la fórmula de las declaraciones protectoras singulares, en los diseños normativos puede identificarse la opción por una aplicación amplia, que permitía dar respuesta a las necesidades de protección de numerosos lugares (Comunidad Valenciana, Baleares), llegándose hasta el extremo de incluir en la propia ley general largas listas de espacios protegidos (Navarra, Canarias).

En ese conjunto de regulaciones pioneras conviene destacar la Ley de Cataluña de 1985, que es la única todavía vigente. Sus contenidos se aproximan a las tradicionales técnicas forestales de protección de la naturaleza, aunque en ella se establece un régimen mucho más moderno que el establecido en la LENP de 1975 y, en algunos extremos, más avanzado incluso que la posterior legislación básica del Estado. La pretensión era configurarla como una ley de conservación de la naturaleza, cuyas disposiciones «se aplicarán a todos los espacios naturales de Cataluña», esto es, tanto a los espacios naturales no especialmente protegidos como a los que fueran objeto de las modalidades especiales de protección. Para los primeros se previeron directamente en la legislación catalana variadas reglas de protección. Los segundos eran los espacios naturales de protección especial en cuyo régimen se incluyeron lo que entonces eran notables novedades, como las relativas a participación, gestión por entidades locales y por particulares, y medidas de desarrollo social y económico de las zonas afectadas. En definitiva, el régimen catalán responde a la vocación de ofrecer respuestas completas a las necesidades de conservación de la naturaleza de todo el territorio autonómico. Muchos de sus contenidos mejoraron y ampliaron la rancia regulación de la LENP de 1975 situándose claramente en la vanguardia de la conservación, por delante incluso de las pautas que el Estado había 
de establecer en la Ley de Conservación de 1989. Quizá ese dato permita explicar el mantenimiento en vigor de la ley catalana, que en todo caso supuso la puesta en marcha efectivamente de un sistema de conservación de la naturaleza en esta comunidad autónoma.

El problema fundamental aquí estriba en que las comunidades autónomas han ido formando sistemas separados de espacios naturales protegidos. Esa separación, si resulta aceptable en términos jurídicos, no lo es bajo la óptica de una política de conservación de la biodiversidad, que precisa, no ya de una gestión centralizada, sino de una gestión coordinada. Para ello, como veremos, la Unión Europea ofrece el magnífico instrumento de la red Natura 2000, que habría de convertirse en el marco de las diferentes redes autonómicas de espacios naturales protegidos.

\section{LA TARDÍA LEGISLACIÓN BÁSICA CONSERVACIONISTA}

En la experiencia española, el desarrollo de las políticas ambientales coincidió con el arrinconamiento del régimen franquista y la puesta en marcha del sistema constitucional. Los motivos determinantes de esas nuevas políticas fueron variados, habiéndose de reconocer una gran influencia a los impulsos internacionales y particularmente a los comunitario-europeos. Ahora bien, junto a ellos, uno de los primeros motores de la atención concedida al medio ambiente puede encontrarse en el compromiso constitucional con su protección, según cabe deducir de las tres grandes cláusulas del art. 45 de la Constitución de 1978: el derecho de todos a un medio ambiente adecuado para el desarrollo de la personalidad, la correspondiente función de garantía de los poderes públicos y el establecimiento de responsabilidades penales, administrativas y civiles para los infractores de la legislación ambiental.

Probablemente el ICONA, aunque en muchos casos fue el blanco de las críticas de la opinión pública, había ido impregnándose de los planteamientos conservacionistas. Prueba de ello podría ser la elaboración de la Ley de Conservación (Ley 4/1989, de 27 marzo, de conservación de los espacios naturales, y de la flora y fauna silvestres), mediante la que se generalizaron y ampliaron las técnicas modernas de gestión de los espacios y los recursos naturales. Aunque una parte considerable de los esfuerzos que se concentraron en esa norma venía determinada por la defensa de un ámbito propio para las competencias estatales, no cabe desconocer los aspectos positivos de la nueva legislación.

Entre los más importantes contenidos de la Ley de Conservación de 1989 ha de destacarse la figura de los planes de ordenación de los re- 
cursos naturales. Se trata de planes que corresponde elaborar y aprobar a las comunidades autónomas a fin de establecer, en función de los espacios y las especies a proteger, las limitaciones generales y específicas respecto de los usos y actividades que hubieran de desarrollarse en el territorio. Cabe considerarlos instrumentos sectoriales de ordenación del territorio: el carácter sectorial derivaría de su vinculación a la política y a los fines de la protección ambiental, mientras que la ubicación entre las técnicas de ordenación del territorio quedaría justificada por sus efectos sobre los usos del suelo, que son los propios de los típicos planes directivos de la ordenación territorial.

La declaración y gestión de los espacios naturales protegidos se atribuyó genéricamente a las comunidades autónomas, permitiéndoles incluso establecer figuras diferentes de conservación. No obstante, a la gestión estatal se reservaron, dentro de la categoría de los parques, los específicamente declarados parques nacionales, así como todos los espacios naturales protegidos que tuvieran por objeto bienes del dominio público marítimo-terrestre o se situaran en el territorio de varias comunidades autónomas. Competencias que hubieron de experimentar importantes reducciones por parte del Tribunal Constitucional en consideración a las competencias autonómicas (STC 102/1995).

Entre las principales técnicas reguladas en la Ley de Conservación cabe mencionar las zonas periféricas de protección, destinadas a evitar impactos ecológicos o paisajísticos procedentes del exterior en los principales espacios naturales protegidos, las áreas de influencia socioeconómica para compensar a las poblaciones afectadas por las limitaciones derivadas de los espacios naturales protegidos y el régimen de protección preventiva para las zonas bien conservadas que resultaren amenazadas por un factor de perturbación que potencialmente pudiera alterar tal estado.

Ha de destacarse también que, por primera vez en nuestra historia, la fauna y la flora, recursos naturales que hasta entonces sólo habían sido objeto de regulación bajo la óptica de su racional explotación en la legislación de caza y pesca, merecieron una singular atención conservacionista. Se previeron medidas de protección de las especies, subespecies y poblaciones de animales y plantas en diferentes situaciones (en peligro de extinción, sensibles a la alteración de su hábitat, vulnerables o de interés especial) mediante planes de recuperación, conservación y manejo de las diferentes categorías de especies. Al objeto de instrumentar tales medidas de protección fue creado el catálogo nacional de especies amenazadas, sin perjuicio de reconocerse la competencia de las comunidades autónomas para establecer otros catálogos y medidas 
adicionales de protección de las especies amenazadas. Con carácter general también el ejercicio de la caza y de la pesca quedó limitado por determinadas reglas sobre protección de las especies.

En definitiva, un destacado conjunto de previsiones que supuso la introducción de las pautas conservacionistas en nuestra legislación básica. La Ley de 1989 sirvió sin duda para dinamizar las intervenciones que correspondían en la materia a las comunidades autónomas, si bien con anterioridad, como hemos visto, en algunas de ellas ya se habían puesto en marcha interesantes sistemas generales de conservación de la naturaleza. Precisamente el protagonismo correspondiente a las comunidades autónomas en la conservación de la naturaleza determinó la supresión del ICONA, cuyas funciones, prácticamente limitadas a los parques nacionales, fueron atribuidas en 1995 al organismo autónomo Parques Nacionales.

La Ley de Conservación de 1989 fue derogada completamente por la vigente Ley del Patrimonio Natural y la Biodiversidad (Ley 42/2007, de 13 diciembre, objeto de una importante reforma por Ley 33/2015, de 21 septiembre). Aunque, en atención a los enfrentamientos competenciales, la Ley de 1989 había sido objeto de diversas reformas parciales, incluso de reformas sobre reformas que habían originado un texto normativo parcheado, precisado de emplear hasta cuatro veces el mismo número en algunos artículos (de bis a quater), lo cierto es que la Ley del Patrimonio Natural presenta tanta continuidad con respecto a la anterior que se hace difícil entender la conveniencia de haber aprobado el nuevo texto legal.

La justificación que cabría encontrar en razones de mejora técnica de la regulación, en realidad serviría para poner de manifiesto las contradicciones de un tipo de norma característico de la legislación ambiental contemporánea, la impuesta por la «tecnología de la conservación», de la que la Ley del Patrimonio Natural resulta ser un prototipo. Las clasificaciones científicas del territorio y de los elementos de la biodiversidad se recogen como normas jurídicas, llegándose, en la incorporación de la normativa internacional y comunitaria que contiene la ley española, a establecer la necesidad de conservar tipos de hábitats como los archipiélagos, costas y superficies emergidas del Báltico boreal, las dunas del mar del Norte y del Báltico, los Machairs de Irlanda, los prados serpentinícolas de Chipre o los bosques de la Europa boreal (anexo I de la Ley del Patrimonio Natural). ¿Motivarán quizá estas relaciones que algún historiador del futuro pueda sostener que en el imperio español del siglo XXI seguía sin ponerse el sol? 


\section{El SignificAdo DE LA REd NATURA 2000}

En la política ambiental de la Unión Europea desempeñan un importante papel las Directivas de Aves (originalmente Directiva 79/409/CEE, incluida actualmente en Directiva 2009/147/CE) y de Hábitats (Directiva 92/43/CEE), especialmente esta última mediante la puesta en marcha de la red Natura 2000. El establecimiento de la red pretende crear un sistema de conservación de la biodiversidad integrado en el territorio, de manera que los espacios naturales protegidos no se presenten como figuras aisladas sino, junto con otras medidas conservacionistas, como elementos de la ordenación territorial.

Las Directivas de Aves y de Hábitats constituyen el último estadio de una evolución apreciable en el derecho internacional, que ha pasado de las limitaciones a la caza y captura de determinados animales en peligro de extinción (ballenas, osos polares) al control del comercio internacional de las especies silvestres amenazadas (Convenio de Washington, 1973) y a la protección de los hábitats de las especies (Convenio de Ramsar, 1971), particularmente en determinadas regiones geográficas (Antártida, Mediterráneo, Alpes). Los directos fundamentos jurídicos y técnicos de la red Natura 2000 se encuentran en los convenios sobre conservación de las especies migratorias de la fauna silvestre (Bonn, 1979), conservación de la vida silvestre y del medio ambiente natural en Europa (Berna, 1979) y diversidad biológica (Río de Janeiro, 1992). En esos tratados multilaterales y en sus variados protocolos de desarrollo, todos ellos suscritos por la Comunidad Europea, fueron estableciéndose entramados institucionales que determinaron la necesidad de unir estrechamente la conservación de las especies a sus hábitats (las áreas de distribución de las especies en Bonn y las zonas protegidas en Berna) a fin de garantizar un estado de conservación satisfactorio, que, finalmente, en Río, se planteó en términos globales para todos los recursos biológicos (incluidos los genéticos), cuya conservación ha de garantizarse in situ por los Estados mediante un sistema de zonas protegidas o sujetas a medidas especiales.

En ese contexto, la Comunidad Europea, mediante la Directiva de Aves de 1979, estableció un sistema general de protección de las aves silvestres, en especial de las migratorias, cuyos planteamientos amplió en la Directiva de Hábitats de 1992 hasta conformar una completa estrategia de conservación de la flora y fauna silvestres y de los hábitats naturales. La idea básica de esas directivas se encuentra en el criterio del desarrollo sostenible, pues se pretende conciliar la conservación de la biodiversidad con el uso del territorio. 
La Directiva de Aves impuso a los Estados miembros la conservación de los hábitats relacionados con las aves silvestres, especialmente de las zonas húmedas empleadas por las aves migratorias. Se exigió a los Estados constituir a tal fin las zonas de especial protección para las aves y gestionarlas conforme a imperativos ecológicos, constituyendo con ellas una «red coherente» de zonas protegidas que respondiera efectivamente a las necesidades existentes.

El alcance de las obligaciones estatales contenidas en la Directiva de Aves está perfectamente asumido por la jurisprudencia comunitaria, que identifica los deberes de los Estados miembros de: a) proteger los espacios que reúnan las características establecidas en la misma; $b$ ) prever medidas efectivas para su conservación; y $c$ ) mantener los efectos de la declaración protectora salvo cuando concurran intereses generales de carácter excepcional. En la formulación de tal doctrina un papel especial correspondió a la STJCE de 2 de agosto de 1993 (caso de las marismas de Santoña, asunto C-355/90), donde se resaltó, de manera entonces ciertamente novedosa, la obligación estatal de declarar las zonas de especial protección conforme a los criterios objetivos y científicos incluidos en los anejos de la Directiva:

Si bien es verdad que los Estados miembros gozan de cierto margen de apreciación en cuanto a la elección de las zonas de protección especial, sin embargo, la clasificación de dichas zonas obedece a ciertos criterios ornitológicos, determinados por la Directiva, tales como, por una parte, la presencia de aves enumeradas en el anejo I y, por otra, la calificación de un hábitat como zona húmeda.

El Tribunal constató concretamente que «las marismas de Santoña constituyen uno de los ecosistemas más importantes de la península Ibérica», correspondiendo al Estado español la obligación estricta de adoptar las medidas precisas para evitar su deterioro. Además, el Tribunal llegó a declarar la insuficiencia de las medidas estatales meramente formales, considerando de ese tipo la simple declaración de las marismas como reserva natural (por Ley 6/1992). Incidió en la misma superficie a proteger, al apreciar que «el territorio de la reserva natural no comprende la totalidad de las marismas», analizando la correspondencia con las exigencias de la Directiva de determinados elementos de perturbación del hábitat (carretera, polígono industrial, instalaciones de acuicultura, vertido de aguas residuales).

Por otra parte, la doctrina de la vinculación de los Estados a sus propias declaraciones de zonas protegidas se había formulado con ante- 
rioridad en la STJCE de 28 febrero 1991 (caso de los diques de Leybucht, asunto C-57/89), donde se estableció que:

[...] los Estados miembros [...] no pueden disponer del mismo margen de apreciación cuando modifican o reducen la superficie de dichas zonas, puesto que ellos mismos en sus declaraciones reconocieron que éstas regulan las condiciones de vida más apropiadas para las especies enumeradas en el anejo de la Directiva 79/409.

De esta manera, «la facultad de los Estados miembros de reducir la superficie de una zona de protección especial sólo puede justificarse por razones excepcionales», razones que respondan «a un interés general superior al del objetivo ecológico contemplado por la directiva». El Tribunal de Justicia rechazó que los intereses económicos y recreativos pudieran justificar normalmente una excepción del régimen de protección; en cambio, consideró que «la prevención del peligro de inundaciones y la protección de la costa» constituían «razones suficientemente serias» para justificar la reducción de la superficie de una zona de protección, "siempre que se limiten al mínimo estricto y conlleven la menor reducción posible de la zona de protección especial». Expresamente negó el Tribunal que la mejora del acceso al puerto de Wreschien pudiera servir para justificar la reducción de la zona de protección, admitiendo tal reducción únicamente por la existencia de ventajas ecológicas derivadas de la construcción del nuevo dique.

Los anteriores planteamientos jurisprudenciales pueden dar idea de las posibilidades derivadas de la puesta en marcha, por la Directiva de Hábitats de 1992, de la red europea Natura 2000, integrada tanto por las zonas de especial protección para las aves como por las nuevas zonas especiales de conservación. Desde luego, en la jurisprudencia comunitaria se advierten las mismas pautas de exigencia a los Estados miembros que las establecidas en relación con la Directiva de Aves.

Frente al procedimiento puramente estatal de declaración de las zonas afectadas por la Directiva de Aves, la declaración de las zonas especiales de conservación en la Directiva de Hábitats se inicia con una fase estatal (lista nacional de lugares con los hábitats correspondientes a las características enumeradas en los anejos de la directiva), seguida de un proceso de decisión por las instituciones comunitarias con una amplia colaboración de los Estados miembros interesados (lista de lugares de importancia comunitaria); finalmente, corresponde a los Estados la declaración y gestión de las correspondientes zonas de especial conservación. 
En todo caso, el procedimiento así conformado responde a criterios científicos que pretenden, no ya preservar unas zonas excepcionales, sino asegurar la conservación de la biodiversidad en todas sus variantes. En tal sentido, de la red ecológica deben formar parte los elementos que "por su estructura lineal y continua o su papel de unión son esenciales para la migración, la distribución geográfica y el intercambio genético de especies silvestres». El territorio comunitario se divide en regiones biogeográficas (alpina, atlántica, continental, macaronésica, mediterránea, canónica, boreal y estépica), debiendo orientarse la selección de las zonas, en palabras del Tribunal de Justicia (STJCE de 11 septiembre 2001, caso Comisión contra Francia), a:

[...] asegurar una cobertura geográfica homogénea y representativa de la totalidad del territorio de cada uno de los Estados miembros a fin de garantizar la coherencia y el equilibrio de la red que todas ellas (las zonas protegidas) forman.

La aprobación de las listas de lugares de importancia comunitaria se produjo con notable retraso respecto a las previsiones temporales de la Directiva de Hábitats, que fijaba para el año 1998 la adopción de dichas listas y para 2004 las subsiguientes declaraciones estatales de las zonas especiales de conservación.

La inclusión de un espacio en las listas comunitarias ha de conllevar el establecimiento por los Estados miembros de las medidas de protección que consideren oportunas. No obstante, de manera inmediata, los espacios incluidos en tal lista quedan sujetos al régimen jurídico que se establece en la misma Directiva de Hábitats, lo que se traduce en la necesidad de someter a evaluación ambiental cualquier plan o proyecto que pueda afectar de forma apreciable a los espacios protegidos, incluidas las actividades que se desarrollen fuera de los mismos. En el procedimiento de evaluación ambiental se admite la posibilidad de desclasificaciones de los lugares o zonas protegidas cuando el Estado miembro afectado considere que «un plan o proyecto deba ser realizado por motivos imperativos de relevante interés público, incluidos motivos de naturaleza social o económica», aunque en tal supuesto, en contrapartida, el Estado deberá adoptar «medidas compensatorias» que garanticen «la coherencia global de la red Natura 2000».

En todo caso, el atractivo diseño de la red europea no puede hacer olvidar los abundantes problemas e incertidumbres que la rodean. En efecto, junto a los considerables retrasos acumulados con respecto a los plazos inicialmente previstos, cabe citar los incumplimientos estatales en la 
presentación de las propuestas, la falta de información entre propietarios de tierras y comunidades rurales, e incluso el excesivo peso otorgado a la perspectiva puramente biológica, olvidando que el patrimonio natural no se puede desconectar del territorio y, en definitiva, de su ordenación. Finalmente, en el caso español se plantea la coexistencia de la red Natura 2000 con las redes de espacios naturales protegidos convencionales.

\section{LA PROBLEMÁTICA INCORPORACIÓN AL ORDENAMIENTO ESPAÑOL}

La incorporación de las Directivas de Aves y de Hábitats a nuestro ordenamiento ha sido tardía e incompleta. La primera se consideró que había sido asumida dentro de las medidas de conservación de las especies de la flora y fauna silvestres establecidas en la Ley de Conservación 4/1989 (arts. 26 a 35), aunque importantes extremos, como la misma figura de las zonas de especial protección de aves, quedaron sin reflejarse en la ley estatal. La Directiva de Hábitats fue directamente traducida al español en el RD 1997/1995, con la única variante de sustituir las referencias originales a los Estados miembros por las comunidades autónomas, a las que se responsabilizó tanto de la iniciativa en la identificación de las listas de lugares susceptibles de ser protegidos como de la declaración de las zonas especiales de conservación y de la fijación de las medidas necesarias. A partir de entonces, en algunas de las primeras leyes generales sobre conservación de la naturaleza de las comunidades autónomas (Navarra, Extremadura, Galicia) se incluyeron breves referencias a la materia, consistentes en obligar al correspondiente Gobierno autonómico a proponer la incorporación a la red Natura 2000 de los espacios naturales protegidos que cumplían los requisitos establecidos en las Directivas de Aves y Hábitats.

No fue sino hasta la reforma de 2003 cuando se introdujo en la Ley de Conservación 4/1989 un capítulo sobre la red ecológica europea Natura 2000, cuyo contenido se limitaba a definir las zonas especiales de conservación y las zonas de especial protección para las aves (arts. 20 ter y quater). La reforma coincidió con la inclusión en algunas leyes autonómicas (La Rioja, Baleares, Cantabria) de más amplias referencias a la materia, repitiéndose en ellas la parte más significativa del régimen jurídico establecido en el RD 1997/1995 y precisándose la competencia del correspondiente Gobierno autonómico para la toma de las principales decisiones. Ese mismo tipo de regulación se aprecia en la vigente Ley del Patrimonio Natural (en redacción establecida por Ley 33/2015), al preverse, junto a los espacios naturales protegidos (parques, reservas, 
áreas marinas, monumentos y paisajes), los espacios protegidos de la red Natura 2000 (arts. 41 a 48), incluyendo las definiciones, los procedimientos a seguir y las medidas de conservación; todo ello, al igual que en la última legislación autonómica citada, como una especie de resumen del RD 1997/1995 y, por tanto, de la Directiva de Hábitats ${ }^{1}$.

En esta situación, cabe observar que nos encontramos ante regulaciones que sólo parcialmente parecen incorporar las obligaciones impuestas en las Directivas comunitarias. La atención se ha centrado en las actuaciones administrativas, técnicas y científicas relativas al cumplimiento de tales obligaciones, lo que se ha traducido en la incorporación casi literal de la Directiva de 1992, la elaboración del inventario nacional de hábitats para responder a las exigencias del anejo I de la misma Directiva y el establecimiento de las listas de espacios que podían ser protegidos; así, hasta llegar a la aprobación de las listas de lugares de importancia comunitaria, previos los debates desenvueltos en los correspondientes seminarios biogeográficos organizados por la Agencia Europea de Medio Ambiente.

El fundamento científico de tales listas ha podido ser riguroso, pero todo el proceso resulta incompleto puesto que en bastantes comunidades autónomas están pendientes de establecerse las medidas definitivas de ordenación de las zonas especiales de conservación y las zonas de especial protección para las aves. En muchos casos, no se dispone de otro régimen aplicable que el previsto con carácter provisional e inmediato en la misma Directiva, que se ha incorporado al ordenamiento jurídico español. Ese régimen consiste, como ya hemos indicado, en un principio general de conservación de las zonas protegidas que resulta atemperado por la obligatoria observancia de procedimientos de evaluación ambiental de los planes, programas y proyectos relativos a tales zonas, los cuales pueden ser autorizados, aun cuando tengan repercusiones negativas en los ámbitos protegidos, si concurren «razones imperiosas de interés público de primer orden» adoptando al mismo tiempo «medidas compensatorias» (Ley del Patrimonio Natural: art. 46).

Obsérvese que no está contemplada la participación adecuada de los interesados en los procedimientos de identificación de los lugares de interés comunitario. Los propietarios afectados ni tan siquiera saben con seguridad que lo son, puesto que las listas de tales lugares se limitan a incluir, en el momento de su misma publicación, la denominación del lugar, la superficie total del mismo y sus límites geodésicos. La situación

1 El RD 1997/1995 continúa en vigor, pues en la disposición derogatoria, apartado 1, de la Ley del Patrimonio Natural 47/2007, incluso tras la importante reforma de 2015, únicamente se derogan sus anejos, que han sido incorporados a la misma ley. 
contrasta con la atención que en el derecho español se ha prestado a los problemas que plantean, bajo la óptica de los derechos de defensa de los ciudadanos afectados, las declaraciones por ley de los parques nacionales y otros espacios naturales protegidos; pues bien, mayor indefensión aún se suscita ante las listas de lugares de interés comunitario, en las que tan difícil resulta saber si una concreta propiedad queda o no incluida, y ello al margen ya de que toda posibilidad de recurso de los particulares frente a las listas esté proscrita al considerarse por la justicia comunitaria que se trata de actos que no afectan directamente a los propietarios, como puede comprobarse en autos del antiguo Tribunal de Primera Instancia de 14 de julio de 2008, dictados en los asuntos T-322/06 (Artos de El Ejido), T-323/06 (Ramblas de Jergal, Tabernas y Sur de Sierra Alhamilla I), T-345/06 (Acebuchales de la Campiña Sur de Cádiz) y T-366/06 (Ramblas de Jergal, Tabernas y Sur de Sierra Alhamilla II), todos ellos declarando la inadmisibilidad de los recursos de anulación interpuestos por propietarios de fincas ubicadas en lugares de importancia comunitaria de la lista correspondiente a la región biogeográfica mediterránea. Las insuficiencias del sistema son notorias, ya que, de cualquier manera, no resulta sensato gestionar una superficie de más del 25 por ciento del territorio nacional, que en algunas comunidades autónomas ronda el 40 por ciento, con tan débiles herramientas.

\section{Perspectivas de la conservación de la BIOdiVERSIDAD}

Es preciso y urgente asumir por completo las consecuencias de la red Natura 2000. Resulta sorprendente que el fenomenal esfuerzo de colaboración administrativa, técnica y científica desarrollado por las comunidades autónomas, el Estado y la Unión Europea carezca del adecuado régimen jurídico que permita el pleno desenvolvimiento de la ambiciosa red ecológica integral. Más admiración aún produce que las comunidades autónomas y el Estado hayan continuado preocupándose, de manera paralela a ese proceso, por los detalles del régimen jurídico de los parques nacionales y los restantes espacios naturales protegidos tradicionales. En verdad, la atención última ha venido determinada por los aspectos competenciales, lo que aparentemente ha impedido al legislador estatal liderar el proceso de implantación de la red Natura 2000 y ha conducido a los legisladores autonómicos a reproducir con mimetismo las sucesivas regulaciones estatales.

La red Natura 2000 no puede equipararse a un conjunto más de espacios naturales protegidos. Debiera de configurarse como el sistema 
mismo de conservación de la biodiversidad del Estado español, articulándolo así adecuadamente en la legislación básica y en la legislación complementaria de las comunidades autónomas. De manera que no habrían de ser las zonas de especial conservación y las zonas de especial protección para las aves las que se considerasen espacios naturales protegidos, sino los mismos parques nacionales y demás espacios naturales protegidos tradicionales los que se integraran en la red Natura 2000.

No sería preciso cambiar ni las instituciones ni las denominaciones consolidadas en nuestra experiencia, pero habría que adaptarlas a las exigencias del proyecto más completo de conservación de la biodiversidad en el que hemos podido participar. Los planes de ordenación de los recursos naturales, con sus amplias vocaciones de ordenación territorial vinculada al sector de la protección del medio ambiente, podrían servir perfectamente para establecer el régimen de uso de los amplios territorios incluidos en la red Natura 2000. Cabría también emplear las diversas categorías de espacios naturales protegidos para establecer los regímenes especiales de mayor protección requeridos en los ámbitos identificados como más sensibles dentro de la misma red ecológica. Regímenes que precisarían de procedimientos de declaración abiertos a los diversos intereses públicos y privados que concurren en la conservación de la biodiversidad, de planificaciones detalladas de las actividades admisibles y, por supuesto, de previsiones organizativas representativas de las Administraciones locales y de los diferentes actores que inciden en la materia.

Era responsabilidad esencial del legislador básico haber adoptado las previsiones que garantizaran plenamente la incorporación a la red Natura 2000 de nuestro sistema de conservación de la biodiversidad. No se ha preocupado de ello, obsesionado, como ha venido estando, en una red de espacios naturales protegidos que sólo puede existir en el papel: la red de parques nacionales, que se refiere a una categoría jurídica, no, desde luego, a una realidad territorial que pueda conectar los espacios naturales protegidos entre sí. Tampoco lo han hecho los legisladores autonómicos, dedicados a formar las propias redes autonómicas de espacios naturales protegidos. La coherencia del sistema nos la puede dar la red europea Natura 2000, siempre que en ella pase verdaderamente a integrarse la red española Natura 2000 compuesta por las redes autonómicas Natura 2000. Con todo lo cual no se está proponiendo aquí ningún replanteamiento de las amplias competencias correspondientes a las comunidades autónomas para la conservación de la biodiversidad, sino una conveniente articulación jurídica de las mismas en la red ecológica que, de verdad, resulta importante. 


\section{ORIENTACIÓN BIBLIOGRÁFICA}

Sobre el régimen jurídico de la LENP de 1975:

T. R. Fernández Rodríguez (1975), «Parques nacionales y protección de la naturaleza», REDA, 5, págs. 215-223.

L. Martín-Retortillo BaQuer (1975), «Aspectos administrativos de la creación y funcionamiento de los parques nacionales», REDA, 6, págs. 343-364.

F. López RAmón (1980), La conservación de la naturaleza, Bolonia: Publicaciones del Real Colegio de España.

Sobre la Ley de Conservación de 1989:

A. García Ureta (1999), Espacios naturales protegidos, Oñati: IVAP.

A. JiMÉNEZ JAÉN (2000), El régimen jurídico de los espacios naturales protegidos, Madrid: McGraw-Hill.

A. Mulero Mendigorri (2002), La protección de espacios naturales en España, Madrid: Mundi-Prensa.

F. DE Rojas Martínez-Parets (2006), Los espacios naturales protegidos, Pamplona: Thomson-Aranzadi.

Sobre la Ley del Patrimonio Natural de 2007:

F. López RAMón (2009), Política ecológica y pluralismo territorial, Madrid: Pons.

Sobre la Red Natura 2000:

A. García UReta (2010), Derecho europeo de la biodiversidad, Madrid: Iustel.

F. López RAMón (2015), "Conectividad y corredores ecológicos en la experiencia española», Revista Aranzadi de Derecho Ambiental, 32, págs. 57-81. 